\title{
Association of Timing of Biliary Drainage with Clinical Outcomes in Severe Acute Cholangitis: A Retrospective Cohort Study
}

\author{
Yimiao Zhu' \\ jiangfeng $T u^{\prime}$ \\ Yu Zhao (iD) ${ }^{2}$ \\ Jiyong Jing ${ }^{3}$ \\ Zhiyuan Dong ${ }^{4}$ \\ Wensheng Pan (1) \\ 'Department of Gastroenterology, \\ Zhejiang Provincial People's Hospital, \\ People's Hospital of Hangzhou Medical \\ College, Hangzhou, Zhejiang, People's \\ Republic of China; ${ }^{2}$ Department of \\ Endocrinology, Zhejiang Provincial \\ People's Hospital, People's Hospital of \\ Hangzhou Medical College, Hangzhou, \\ Zhejiang, People's Republic of China; \\ ${ }^{3}$ Teaching Department, Zhejiang \\ Provincial People's Hospital, People's \\ Hospital of Hangzhou Medical College, \\ Hangzhou, Zhejiang, People's Republic of \\ China; ${ }^{4}$ Qingdao University Medical col- \\ lege, Qingdao, Shandong, People's \\ Republic of China
}

Purpose: The guidelines recommend urgent biliary drainage (BD) for severe acute cholangitis, without a clear definition of "urgent". To explore the optimal time, we identified the impact of timing of BD on clinical outcomes in severe acute cholangitis.

Patients and Methods: A retrospective study of patients with severe acute cholangitis was conducted based on the Multiparameter Intelligent Monitoring in Intensive Care III (MIMICIII) database. Multivariable regressions were used to identified the effect of timing of BD on in-hospital mortality, 30-day mortality, and the length of stay (LOS) in hospital and the intensive care unit (ICU) with adjustment for confounding factors.

Results: A total of 106 severe acute cholangitis patients underwent BD with a median time of 14.14 hours (IQR: 7.60-32.59). Among them, 67.9\% were performed within 24 hours and $80.2 \%$ within 48 hours. Median length of stay was 2.65 days (IQR: $1.70-5.12$ ) in the ICU and 7.54 days (IQR: 4.49-17.17) in hospital. The in-hospital and 30-day mortality rates were $13.2 \%$ and $14.2 \%$, respectively. On multivariate analysis, every 1-day delay of BD increased 1.49 days of stay in hospital ( $\mathrm{P}<0.0001)$. Delayed BD ( $>48$ hours) was linked with 5.56 days longer ICU LOS $(\mathrm{P}=0.0096)$, while urgent $\mathrm{BD}(<24$ hours $)$ did not significantly shorten the ICU stay ( $\mathrm{P}=0.0997)$. No significant increase was observed on in-hospital mortality ( $\mathrm{OR}=$ 1.03 ; 95\% CI $0.93-1.13$ ) nor 30-day mortality ( $\mathrm{OR}=1.01$; 95\% CI $0.87-1.14$ ) with BD delay in this population.

Conclusion: In severe acute cholangitis patients, delay in BD increased in-hospital LOS. BD after 48 hours was associated with longer ICU LOS. Yet, BD within 24 hours did not significantly reduce the mortality nor shortened the ICU LOS.

Keywords: acute cholangitis, biliary drainage, endoscopic retrograde cholangiopancreatography, ERCP, length of stay LOS, mortality

\section{Introduction}

Acute cholangitis (AC) is an ascending bacterial infection of the bile duct, presenting heterogeneously in clinical entity from mild to severe in a rapid progression pattern. The development of early recognition and timely treatment of AC, including biliary drainage (BD), fluid resuscitation and antibiotic administration, have improved the clinical outcome dramatically. However, the mortality remains $10-$ $30 \%$ in the setting of severe acute cholangitis. ${ }^{1-3}$

The Tokyo Guidelines 2018 (TG18) recommend urgent biliary drainage for patients with severe acute cholangitis, lacking evidenced based data or limited to expert opinion. ${ }^{4}$ Despite updates of the guidelines, the time frame of BD is not
Correspondence: Wensheng Pan Department of Gastroenterology, Zhejiang Provincial People's Hospital, People's Hospital of Hangzhou Medical College, I58 Shangtang Road, Xiacheng District, Hangzhou, 3100 14, People's Republic of China

Tel +86-057I-8589-343I

Fax+86-057I-8513-1448

Email wspan223@163.com 
specified and the definition of "early" or "urgent" is unclear. A number of studies have reported that delayed biliary drainage ( $>48$ hour or $>72$ hour) worsened the clinical outcome. ${ }^{1,5-7}$ Still, it is in doubt whether patients with severe acute cholangitis can safely delay BD by 24 or 48 hours to allow adequate resuscitation, in order to lower the procedure complications, without increasing mortality. Experts' opinions advocated an urgent biliary decompression, and even some proposed "as early as possible" or "less than 12 hours". 8 On the other hand, researchers claimed that the "weekend effect" had no impact on clinical outcomes such as mortality and length of stay in hospital in acute cholangitis. ${ }^{9-11}$ Hakuta et al suggested no association of timing of endoscopic biliary drainage with clinical outcomes in patients with non-severe acute cholangitis. $^{12}$ However, little investigation has been focused on the timing of BD in the severe acute cholangitis population. Given the lack of evidenced based data, we aimed to explore the effect of timing of biliary drainage on clinical outcomes defined as mortality and length of stay (LOS) in hospital and the intensive care unit (ICU) in patients with severe acute cholangitis.

\section{Patients and Methods}

\section{Study Design}

This was a retrospective cohort study, which extracted the data from MIMIC-III (the Medical Information Mart for Intensive Care III V1.4). ${ }^{13}$ MIMIC-III is a single-center database that contains 53,432 stays for adult patients in critical care units at Beth Israel Deaconess Medical Center Boston, MA, USA between 2001 and 2012. The data was from version 1.4, updated on 2 September 2016.

\section{Study Population}

Adult patients ( $>18$ years old) in their first ICU stay with ICD-9 diagnosis code of $57,451,57,491,5762$ or 5761 were eligible for inclusion. According to the diagnoses criteria and severity criteria of Tokyo Guidelines 2018 (TG18) within the first 24 hours after admission, patients with severe acute cholangitis were selected. Then we excluded patients without biliary drainage or with missing data of BD timing.

\section{Study Variables}

We extracted from the MIMIC-III the demographic data and biochemistry data within the first 24 hours after admission, including age, sex, race, albumin, bicarbonate, bilirubin, creatinine, lactate, platelet count, blood urea nitrogen (BUN), white blood cell (WBC), international normalized ratio (INR), aspartate aminotransferase (AST), alanine aminotransferase (ALT), alkaline phosphatase (ALP) and presence of bacteremia. The median value was taken when there were multiple measurements of biochemistry indexes. The Sequential Organ Failure Assessment (SOFA) was measured as severity grading and modified Elixhauser comorbidity index (ECI, Van Walraven version) was applied to assess the cocomorbidities. ${ }^{14}$ Organ failure was defined according to the severity criteria of the Tokyo Guidelines 2018 (TG18), applying the GCS score, blood pressure and biochemistry data. ICD-9 diagnosis codes and ICD-9 procedure codes of each patient were extracted to record the etiology of cholangitis and type of drainage procedure, respectively. Anti-microbials prescription were obtained, which referred to the types of antibiotics within the first 24 hours.

\section{Outcomes}

The exposure was the timing of biliary drainage, which was defined as the duration from admission time to the first biliary drainage procedure (ERCP or PBD, percutaneous biliary drainage) time. The primary outcome of this study were in-hospital mortality and 30-day mortality which was defined as death occurring within 30 days from the date of admission to hospital. The secondary outcomes included the length of stay (LOS) in hospital and the ICU.

\section{Statistical Analysis}

Continuous variables including age, ECI, SOFA, number of organ failures, biochemistry profiles, timing of biliary drainage and LOS were expressed as mean \pm standard deviation or median with interquartile range. Sex, race, organ failure, etiology of acute cholangitis, type of antimicrobials, procedures of biliary Drainage, in-hospital mortality and 30-day mortality were defined as categorical variables and reported as percentages. The comparison of BD timing between survivors and nonsurvivors were analyzed with the Mann-Whitney test. Length of stay difference among different BD timing groups ( $<24$ hours, 24-48 hours, $>48$ hours) were analyzed with the Kruskal-Wallis test.

We applied multivariable linear regression models evaluating the association between timing of biliary drainage (days) and length of stay in the ICU and hospital. The 
BD timing was analyzed as a continuous variable and categorical variable with 24 hours or 48 hours as the cutoff, respectively. Multicollinearity in regression models was evaluated by calculating the variance inflating factor. Values of the variance inflating factor exceeding 10 were considered to indicate multicollinearity. Excluding collinearity variables, the clinical meaningful variables or ones that effected the linear regression coefficients estimate by more than $10 \%$, were selected as confounders to adjust in the final model, which including cardiovascular dysfunction, neurological dysfunction, etiology of bile duct stone and ECI. Interaction and stratified analyses were conducted according to age grouping (above and below 75 years), bilirubin level (above and below $5 \mathrm{mg} / \mathrm{dL}$ ), and ECI score (above and below 10) with adjusted confounders.

Multivariable logistic regression models were applied to access for the 30-day mortality or in-hospital mortality with BD timing. Multicollinearity in regression models was evaluated by calculating the variance inflating factor. Values of the variance inflating factor exceeding 10 were considered to indicate multicollinearity. Excluding collinearity variables. The clinically meaningful variables and variables that showed a univariate relationship with the outcome $(\mathrm{p}<0.1)$ were considered as candidate confounders. The top three effected the initial regression coefficients, were adjusted in the final model, included percutaneous drainage, cardiovascular dysfunction, bicarbonate and ECI. The relationship between BD timing and mortality might not be linear, thus adjusted smoothing spline plots of mortality by BD timing were investigated to explore the relationship of these two. Interaction and stratified analyses were conducted according to age, bilirubin, bacteremia and ECI with adjusted confounders.

The details of missing data were displayed in the supplementary materials Figure S1. In analysis, the missing data were acquired with 5 sets of data via the multiple imputation method and a chained equation approach method in the R MI procedure, to account for missing data. The distributions of all the variables of missing data were of similar values with the imputation data (Table S1). Multivariable regression models applying the original data were undertaken in the sensitivity analysis (Tables S2-S3).

All of the analyses were performed with the $\mathrm{R}$ package (version 3.6.0) and EmpowerStats (http://www.empower stats.com, X\&Y Solution, Inc., Boston, MA). All tests were 2-sided, and $\mathrm{P}<0.05$ was considered statistically significant.

\section{Results \\ Demographic Data and Baseline Characteristics}

A total of 106 severe acute cholangitis patients with timing of BD were enrolled in the analysis cohort. The flow diagram of the study population is shown in Figure 1. The characteristics of the population are summarized in Table 1. During the study period, 106 patients (median age, 75 years; median SOFA score, 14; median comorbidity ECI score, 10) are of $84.9 \%$ benign etiology and $15.1 \%$ malignant etiology. In the cohort, cardiovascular dysfunction was detected in 67/106 (63.2\%), neurological dysfunction in $46 / 106(43.4 \%)$, respiratory dysfunction in $38 / 106(86.4 \%)$, renal dysfunction in $31 / 106(29.2 \%)$, hepatic dysfunction in 49/106 (46.2\%) and hematological dysfunction in 29/106 (27.4\%). The median of numbers of organ failures is 4 . Patients underwent the biliary drainage with a median time of 14.14 hours (IQR: 7.60-32.59). Among them, 67.9\% underwent biliary drainage within 24 hours, 80.2\% within 48 hours and $82.1 \%$ within 72 hours, which included $70.8 \%$ stent/tube insertion, $31.1 \%$ stone extraction, $40.6 \%$ procedures on duodenal papilla and $20.8 \%$ percutaneous drainage. The bacteremia presented in $34.9 \%$ severe acute cholangitis patients and $61.3 \%$ patients were prescribed a combination of antimicrobial agents. Median length of stay was 2.65 days (IQR: 1.70-5.12) in the ICU and 7.54 days (IQR: 4.4917.17) in hospital. The in-hospital and 30-day mortality rates were $13.2 \%$ and $14.2 \%$ respectively.

\section{The Association Between Timing of Biliary Drainage and Length of Stay}

Median length of stay was 2.65 days (IQR: 1.70-5.12) in the ICU and 7.54 (IQR: 4.49-17.17) in hospital, with a significant increase across the $<24$ hours, $24-48$ hours and $\geq 48$ hours groups (in-hospital LOS, $\mathrm{P}<0.0001$; ICU LOS, $\mathrm{P}=0.032$ ) (Figure 2).

The multivariate logistic regression suggested that every delayed day of BD increased LOS by 1.49 days (95\% CI 1.09-1.89; P < 0.0001) (Table 2). The patients who underwent BD after 24 hours had 11.86 days (95\% CI 5.14-18.59; $\mathrm{P}=0.0008)$ longer in-hospital LOS, compared with BD within 24 hours. When performed after 48 hours, it increased to 20.91 days (95\% CI 13.82-28.00; 


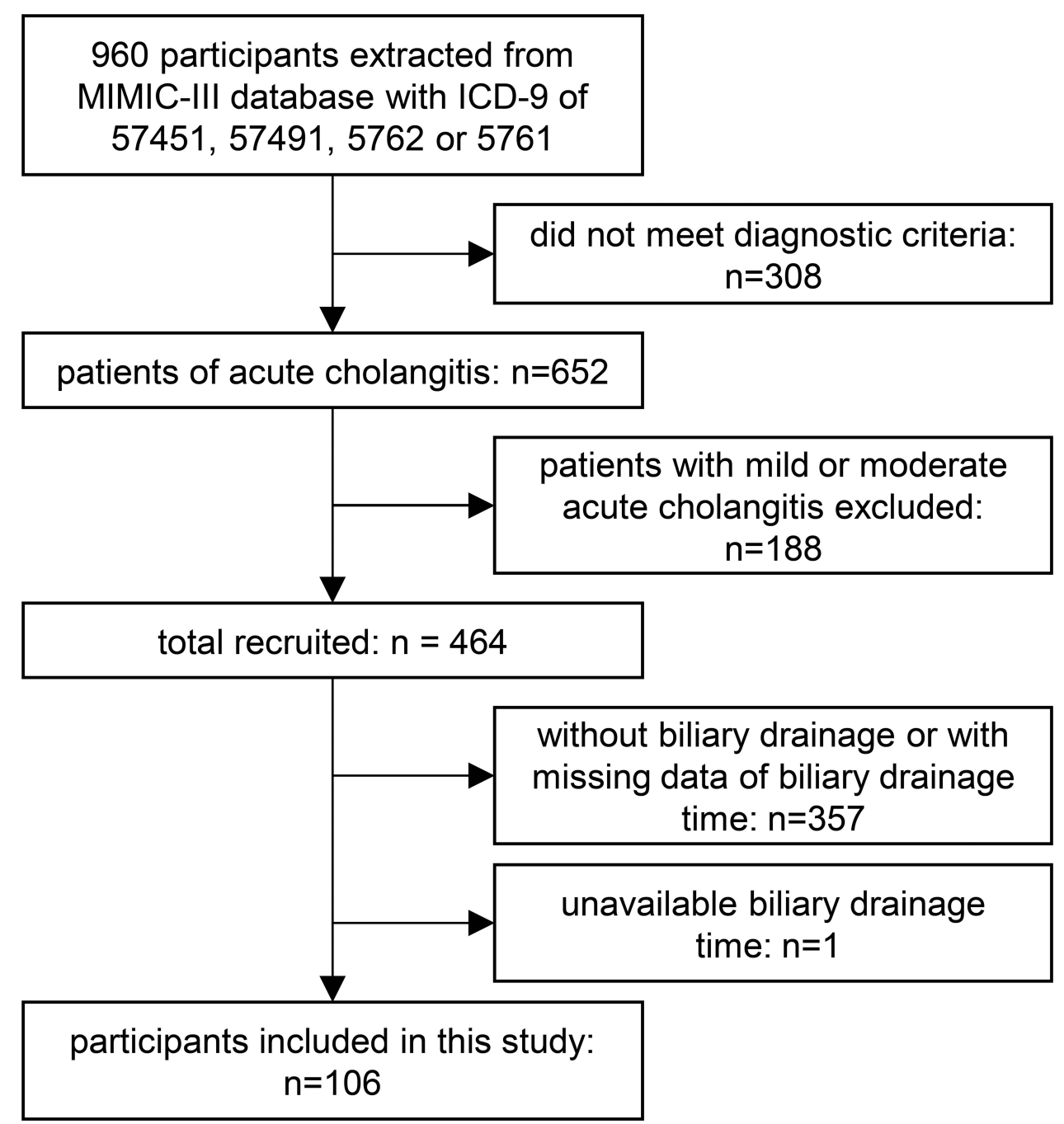

Figure I Flow chart of the study participants.

$\mathrm{P}<0.0001$ ) (Table 2 ). The sensitivity analyses involving the original data was consistent with it (Table S2). The interaction analysis indicated that bilirubin level ( $\mathrm{P}$ for interaction $=0.005)$ and ECI score $(\mathrm{P}$ for interaction $=$ 0.002) might play an interactive role in the association between $\mathrm{BD}$ timing and in-hospital LOS (Figure 3).

The ICU LOS increased by 0.47 days ( $95 \%$ CI $0.23-0.71$; $\mathrm{P}=0.0002$ ) with every delayed day of biliary drainage in multivariable linear regression models (Table 3). And different effects of BD timing on the ICU LOS were detected in different aging group $(\mathrm{P}=0.005)$, but was stable in subgroup analyses in different bilirubin or ECI scored patients (Figure 4). When using 24 hours as a cut-off, there was no difference in the ICU LOS (P = 0.0997); while delayed BD ( $\geq 48$ hours) related to a 5.56 (95\% CI 1.43-9.68; $\mathrm{P}=0.0096$ ) days prolonged ICU LOS (Table 3). The sensitivity analyses involving the original data was consistent with it (Table S2).

\section{The Association Between Timing of Biliary Drainage and Mortality}

The total in-hospital and 30-day mortality rates were $13.2 \%$ and $14.2 \%$ respectively, with $11.1 \%$ and $13.9 \%$ in $<24$ hours group, with $15.4 \%$ and $7.7 \%$ in $24-48$ hours group, and with $19.0 \%$ and $19.0 \%$ in $>48$ hours (Figure 5 ). There was no significant difference in timing of $\mathrm{BD}$ between survivors and nonsurvivors (in-hospital mortality, $\mathrm{P}=0.52 ; 30$-day mortality, $\mathrm{P}=0.78$ ) (Figure 6).

After adjusting for potential confounders, a linear relationship between BD timing and mortality was observed according to smoothing spline plots (Figure S2). However, there was no significant increase effect on both in-hospital $(\mathrm{OR}=1.03 ; 95 \%$ CI $0.93-1.13 ; \mathrm{P}=0.9327)$ and 30-day mortality $(\mathrm{OR}=1.01 ; 95 \%$ CI $0.87-1.14 ; \mathrm{P}=0.9461)$ with $\mathrm{BD}$ delay in adjusted multivariable logistic regression models 
Table I Baseline Characteristics of 106 Patients with Severe Acute Cholangitis

\begin{tabular}{|c|c|c|}
\hline \multicolumn{2}{|c|}{ Variables } & Total $(n=106)$ \\
\hline \multicolumn{2}{|c|}{ Age (years) } & $75.4[63.77,83.47]$ \\
\hline \multicolumn{2}{|c|}{ Male, n (\%) } & $54(50.9)$ \\
\hline $\begin{array}{l}\text { Race, } \\
\text { n (\%) }\end{array}$ & $\begin{array}{l}\text { White } \\
\text { Black } \\
\text { Asian } \\
\text { Hispanic/Latino } \\
\text { Other }\end{array}$ & $\begin{array}{l}75(70.8) \\
4(3.8) \\
5(4.7) \\
6(5.7) \\
16(15.1)\end{array}$ \\
\hline $\begin{array}{l}\text { Severity } \\
\text { scores }\end{array}$ & $\begin{array}{l}\text { ECl } \\
\text { SOFA }\end{array}$ & $\begin{array}{l}10.00[5.00,17.00] \\
14.00[12.00,17.00]\end{array}$ \\
\hline $\begin{array}{l}\text { Organ } \\
\text { failure }\end{array}$ & $\begin{array}{l}\text { Number of organ failures } \\
\text { Cardiovascular dysfunction, } \\
\text { n (\%) } \\
\text { Neurological dysfunction, } \\
\text { n (\%) } \\
\text { Respiratory dysfunction, n (\%) } \\
\text { Renal dysfunction, n (\%) } \\
\text { Hepatic dysfunction, n (\%) } \\
\text { Hematological dysfunction, } \\
\text { n (\%) }\end{array}$ & $\begin{array}{l}4.00[2.00,4.00] \\
67(63.2) \\
46(43.4) \\
38(86.4) \\
31(29.2) \\
49(46.2) \\
29(27.4)\end{array}$ \\
\hline \multicolumn{3}{|c|}{ Etiology of acute cholangitis } \\
\hline \multicolumn{2}{|c|}{ Benign etiology, n (\%) } & $90(84.9)$ \\
\hline & $\begin{array}{l}\text { Bile duct stone } \\
\text { Inflammatory stricture } \\
\text { Liver transplantation } \\
\text { Other }\end{array}$ & $\begin{array}{l}60(56.6) \\
12(11.3) \\
5(4.7) \\
13(12.3)\end{array}$ \\
\hline \multicolumn{2}{|c|}{ Malignant etiology, n (\%) } & $16(15.1)$ \\
\hline & $\begin{array}{l}\text { Cholangiocarcinoma } \\
\text { Pancreatic cancer } \\
\text { Ampullary cancer } \\
\text { Other }\end{array}$ & $\begin{array}{l}4(3.8) \\
4(3.8) \\
2(1.9) \\
6(5.7)\end{array}$ \\
\hline \multicolumn{2}{|c|}{ Stent dysfunction, $\mathrm{n}(\%)$} & $14(13.2)$ \\
\hline \multicolumn{3}{|c|}{$\begin{array}{l}\text { Biochemistry (within first } 24 \text { hours of } \\
\text { admission) }\end{array}$} \\
\hline & $\begin{array}{l}\text { Albumin }(\mathrm{g} / \mathrm{dl}) \\
\text { Bicarbonate }(\mathrm{mEq} / \mathrm{L}) \\
\text { Bilirubin }(\mathrm{mg} / \mathrm{dL}) \\
\text { Creatinine }(\mathrm{mg} / \mathrm{dL}) \\
\text { Lactate }(\mathrm{mmol} / \mathrm{L})\end{array}$ & $\begin{array}{l}2.82(0.57) \\
23.55(4.56) \\
5.25[2.90,8.00] \\
1.40[0.90,2.20] \\
2.10[1.35,3.55]\end{array}$ \\
\hline
\end{tabular}

(Continued)
Table I (Continued).

\begin{tabular}{|c|c|c|}
\hline \multicolumn{2}{|l|}{ Variables } & Total $(n=106)$ \\
\hline \multicolumn{2}{|c|}{$\begin{array}{l}\text { Biochemistry (within first } 24 \text { hours of } \\
\text { admission) }\end{array}$} & \\
\hline & $\begin{array}{l}\text { Platelet count }\left(10^{9} / \mathrm{L}\right) \\
\text { BUN }(\mathrm{mg} / \mathrm{dL}) \\
\text { WBC }\left(10^{9} / \mathrm{L}\right) \\
\text { INR } \\
\text { AST }(\mathrm{U} / \mathrm{L}) \\
\text { ALT }(\mathrm{U} / \mathrm{L}) \\
\text { ALP }(\mathrm{U} / \mathrm{L})\end{array}$ & $\begin{array}{l}177.02(106.99) \\
31.72(18.21) \\
17.78(8.69) \\
1.50[1.30,1.90] \\
146.00[69.00,272.00] \\
133.00[66.00,263.00] \\
224.00[143.00, \\
356.00]\end{array}$ \\
\hline \multicolumn{2}{|c|}{ Bacteremia, n (\%) } & $37(34.9)$ \\
\hline \multicolumn{3}{|c|}{ Anti-microbials, n (\%) } \\
\hline & $\begin{array}{l}\beta \text {-lactam/ } \beta \text {-lactamase inhibitor } \\
\text { combination penicillins } \\
\text { Third or fourth generation } \\
\text { cephalosporins } \\
\text { Carbapenems } \\
\text { Fluoroquinolones } \\
\text { Anti-gram-positive agents } \\
\text { Nitroimidazoles } \\
\text { Combination of anti-microbial } \\
\text { agents, } \mathrm{n}(\%)\end{array}$ & $\begin{array}{l}87(82.1) \\
10(9.4) \\
4(3.8) \\
28(2.6) \\
49(26.2) \\
23(21.7) \\
65(61.3)\end{array}$ \\
\hline \multicolumn{2}{|c|}{ Timing of biliary drainage (hours) } & $14.14[7.60,32.59]$ \\
\hline & $\begin{array}{l}<24 \text { hours } \\
<48 \text { hours } \\
<72 \text { hours }\end{array}$ & $\begin{array}{l}72(67.9) \\
85(80.2) \\
87(82.1)\end{array}$ \\
\hline \multicolumn{3}{|c|}{ Procedures of biliary Drainage, $\mathrm{n}(\%)$} \\
\hline & $\begin{array}{l}\text { Stent/tube } \\
\text { Stone extraction } \\
\text { Sphincterotomy/papillotomy/ } \\
\text { dilation of ampulla } \\
\text { Percutaneous drainage }\end{array}$ & $\begin{array}{l}75(70.8) \\
33(31.1) \\
43(40.6) \\
22(20.8)\end{array}$ \\
\hline \multicolumn{2}{|c|}{ Timing of biliary drainage (hours) } & $14.14[7.60,32.59]$ \\
\hline & $\begin{array}{l}<24 \text { hours } \\
<48 \text { hours } \\
<72 \text { hours }\end{array}$ & $\begin{array}{l}72(67.9) \\
85(80.2) \\
87(82.1)\end{array}$ \\
\hline $\begin{array}{l}\text { Length of } \\
\text { stay } \\
\text { Survival }\end{array}$ & $\begin{array}{l}\text { In-hospital (days) } \\
\text { ICU (days) } \\
\text { In-hospital mortality, n (\%) } \\
\text { 30-day mortality, n (\%) }\end{array}$ & $\begin{array}{l}7.54[4.49,17.17] \\
2.65[1.70,5.12] \\
14(13.2) \\
15(14.2)\end{array}$ \\
\hline
\end{tabular}

Notes: data presented are mean \pm SD, median (QI-Q3), or $\mathrm{N}(\%)$.

Abbreviations: $\mathrm{ECl}$ (vanWalRaven), Elixhauser comorbidity index; SOFA, Sequential Organ Failure Assessment; BUN, blood urea nitrogen; WBC, white blood cell; INR, international normalised ratio; ALT, alanine aminotransferase; AST, aspartate aminotransferase; ALP, alkaline phosphatase; ICU, intensive care unit. 


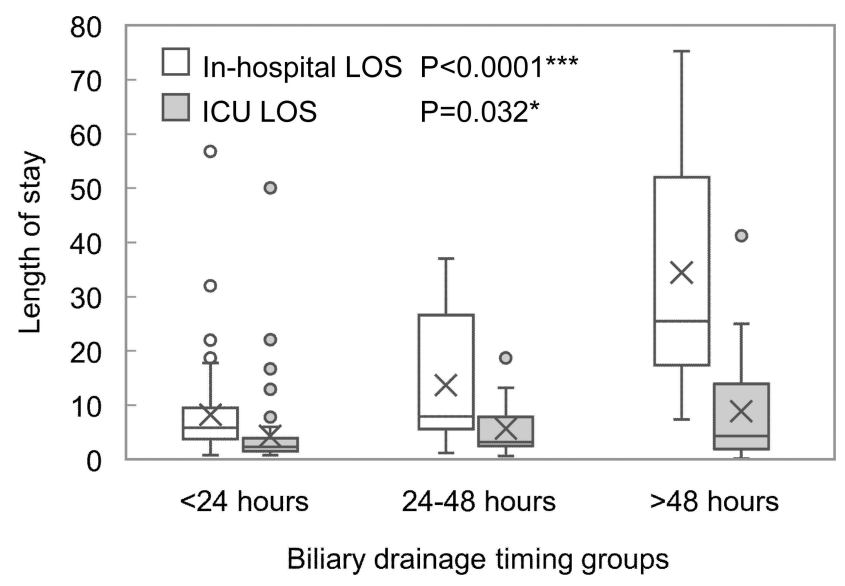

Figure 2 Length of stay of in-hospital and ICU among different biliary drainage timing groups ( $<24$ hours, $24-48$ hours, and $>48$ hours). ${ }^{*} \mathrm{P}<0.05$ and $* * * *$ 0.001 .

(Table 4). The sensitivity analyses applying the original data was consistent with it (Table S3). According to subgroup analyses, the results of in-hospital mortality were stable for different ages, bilirubin levels, ECI scores and bacteremia conditions of patients (Figure S3a). The interaction analysis indicated that the presence of bacteremia $(\mathrm{P}$ for interaction $=$ $0.010)$ might play an interactive role in the association between BD timing and 30-day mortality (Figure S3b).

\section{Discussion}

In this retrospective study, we investigated the timing of biliary drainage (BD) effect on clinical outcomes in severe acute cholangitis patients, taking competing clinical risk factors into account. Overall, every 1-day delay of BD timing increased LOS in hospital by 1.49 (95\% CI 1.09
1.89; $\mathrm{P}<0.0001)$ days. Bilirubin level $(\mathrm{P}$ for interaction $=$ $0.005)$ and ECI score ( $P$ for interaction $=0.002)$ might play an interactive role in it. Regarding the ICU LOS, delayed BD ( $>48$ hours) was linked with 5.56 (95\% CI 1.43-9.68; $\mathrm{P}=0.0096)$ days longer stay, while urgent $\mathrm{BD}$ patients $(<24$ hours) had no significant difference in ICU LOS, compared with those who underwent BD after 24 hours $(P=0.0997)$. There was no significant increase effect with $\mathrm{BD}$ delay on in-hospital mortality $(\mathrm{OR}=1.03 ; 95 \%$ CI $0.93-1.13$; $\mathrm{P}=$ $0.9327)$ and 30 -day mortality $(\mathrm{OR}=1.01 ; 95 \%$ CI $0.87-$ $1.14 ; \mathrm{P}=0.9461)$ in our severe acute cholangitis population.

Acute cholangitis is considered an emergent condition, especially severe acute cholangitis, which advances in a rapid way. The optimal treatment strategy, namely early recognition, biliary drainage procedures, fluid resuscitation, and prompt antibiotics introduction, has decreased the mortality from $50 \sim 60 \%$ to approximately $20 \%{ }^{15,16}$ Our results have testified that an earlier BD timing benefits patients with shorter in-hospital LOS, in accordance with a number of studies and we further proved that the benefit maintained in the severe acute cholangitis. ${ }^{5-7,17,18}$ Bilirubin level as well as ECI score might impact the effects.

However, for the severe acute cholangitis patient, it is highly debatable what the optimal strategy is: performing biliary drainage procedures as early as possible or delaying the procedures until stabilization after adequate resuscitation? Our data concluded that delayed BD ( $\geq 48$ hours) was linked to a 5.56 day increase of ICU stay. However, urgent BD $(<24$ hours) patients had no significant difference on ICU LOS. In patients older than 75 , the prolonged ICU LOS effects of BD delaying might be more obvious.

Table 2 Multivariable Linear Regression Models Evaluating the Association Between Timing of Biliary Drainage and in-Hospital Length of Stay (LOS)

\begin{tabular}{|c|c|c|c|c|c|c|}
\hline \multirow[t]{2}{*}{ Variables } & \multicolumn{2}{|c|}{ Crude $(\mathrm{N}=106)$} & \multicolumn{2}{|c|}{ Model I $(N=106)$} & \multicolumn{2}{|c|}{ Model $2(N=106)$} \\
\hline & $\beta(95 \% \mathrm{Cl})$ & $P$ value & $\beta(95 \% \mathrm{Cl})$ & $P$ value & $\beta(95 \% \mathrm{Cl})$ & $P$ value \\
\hline Timing of biliary drainage (days) & $\mathrm{I} .84(\mathrm{I} .45,2.22)$ & $<0.0001 * * *$ & $1.72(1.33,2.10)$ & $<0.0001 * * *$ & $1.49(1.09,1.89)$ & $<0.000 I^{* * *}$ \\
\hline $\begin{array}{l}\text { Timing of biliary drainage (hours) } \\
<24 \\
\geq 24\end{array}$ & $\begin{array}{l}\text { Ref } \\
18.45(12.43,24.46)\end{array}$ & $<0.0001 * * *$ & $\begin{array}{l}\text { Ref } \\
16.66(10.61,22.70)\end{array}$ & $<0.0001 * * *$ & $\begin{array}{l}\text { Ref } \\
\text { II.86 (5.14, 18.59) }\end{array}$ & $0.0008 * * *$ \\
\hline $\begin{array}{l}\text { Timing of biliary drainage (hours) } \\
<48 \\
\geq 48\end{array}$ & $\begin{array}{l}\text { Ref } \\
25.58(19.05,32.11)\end{array}$ & $<0.0001 * * *$ & $\begin{array}{l}\text { Ref } \\
25.14(18.71,31.57)\end{array}$ & $<0.0001 * * *$ & $\begin{array}{l}\text { Ref } \\
20.91 \quad(13.82,28.00)\end{array}$ & $<0.000 I^{* * *}$ \\
\hline
\end{tabular}

Notes: data presented are $\beta$ s and $95 \%$ Cls. Adjust I model adjusts for age and sex; Adjust II model adjusts for adjust I + ECl, Percutaneous drainage, Cardiovascular dysfunction and bile duct stone as etiology. $* * * \mathrm{P}<0.001$

Abbreviation: $\mathrm{ECl}$ (vanWalRaven), Elixhauser comorbidity index. 


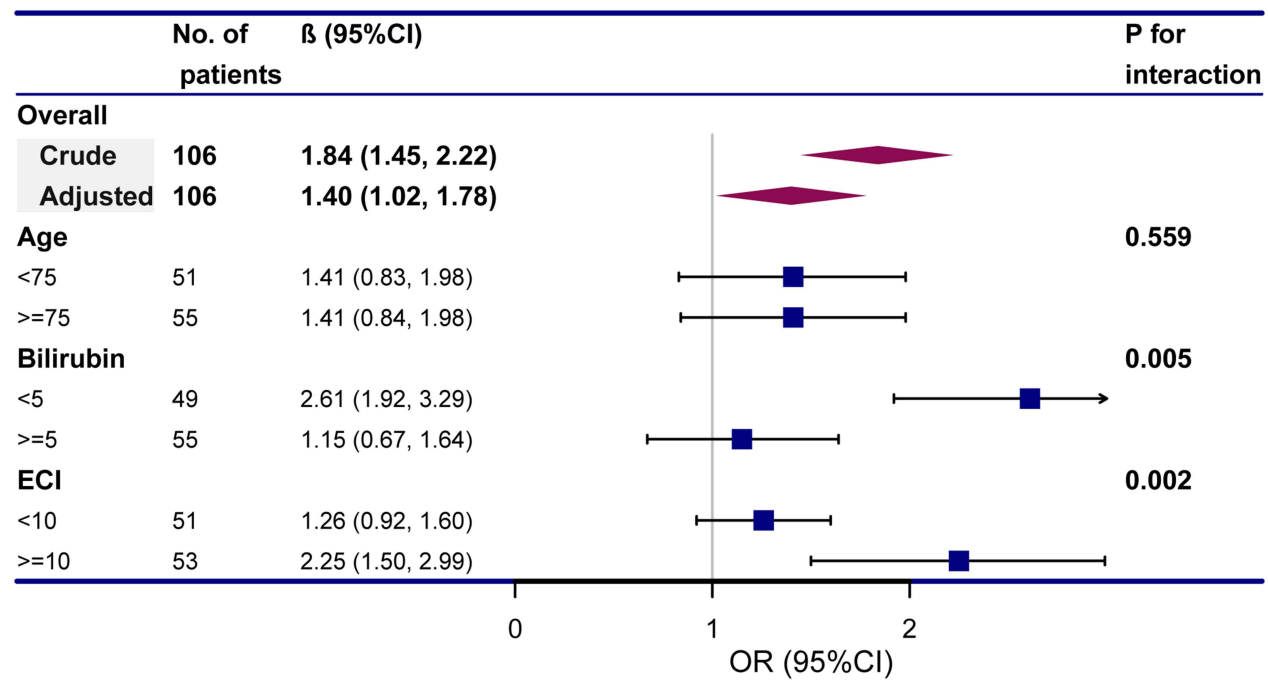

Figure 3 Subgroup analyses of the association between timing of biliary drainage (days) and length of stay of in-hospital. Notes: Each stratification adjusted for all the factors (age, sex, bilirubin, ALP and ECI) except the stratification factor itself.

However, with BD timing delay, no significant increase effect on in-hospital and 30-day mortality rate was observed in this severe acute cholangitis population. A few studies also suggested no decrease on odds of mortality with urgent (defined as within 24 hours) or early (within 48 hours) biliary drainage. Aboelsoud et al enrolled the acute cholangitis patients from MIMIC-III. They found that using 24 hours or 48 hours as a cut-off, there was no difference on in-hospital mortality (OR = $0.47 ; 95 \%$ CI $0.17-1.29 ; \mathrm{p}=0.146$ ) or 28 -day mortality $(\mathrm{OR}=0.61 ; 95 \%$ CI $0.24-1.53 ; \mathrm{p}=0.297)$. Though they reported a shorter ICU LOS in patients who underwent BD within 24 hours, the associated confounders as comorbidity and severity of the disease were not adjusted on the result. ${ }^{17}$ One retrospective multicenter cohort analysis had a conclusion that the rate of ERCP and the timing from admission to ERCP were not associated with adverse outcomes, even when stratified by 24-hour intervals. ${ }^{18}$ Interestingly, another retrospective cohort of 203 patients, taking persistent organ failure as outcome, revealed that delayed ( $>48 \mathrm{~h}$ ) ERCP were associated with the outcome, while procedures within 24 hourswere not $(\mathrm{AOR}=2.1$; $95 \% \mathrm{CI}=0.8-5.7) .{ }^{1}$ Navaneethan compared the persistent OF and/or 30-d mortality among patients in every 24-hour interval, and there were no significant associations with the outcome in the 24-48 hours group and 48-72 hours group according to multivariate analysis. ${ }^{6}$ Young ji et al observed no decrease in mortality among those who had ERCP on the day of admission in both Tokyo grade (TG) I, TG II and TG III cohorts in a national database analysis

Table 3 Multivariable Linear Regression Models Evaluating the Association Between Timing of Biliary Drainage and ICU LOS

\begin{tabular}{|c|c|c|c|c|c|c|}
\hline \multirow[t]{2}{*}{ Variables } & \multicolumn{2}{|c|}{ Crude $(\mathrm{N}=106)$} & \multicolumn{2}{|c|}{ Model I $(N=106)$} & \multicolumn{2}{|c|}{ Model $2(\mathrm{~N}=106)$} \\
\hline & $\beta(95 \% \mathrm{Cl})$ & $P$ value & $\beta(95 \% \mathrm{Cl})$ & $P$ value & $\beta(95 \% \mathrm{Cl})$ & $P$ value \\
\hline Timing of biliary drainage (days) & $0.43(0.22,0.65)$ & $0.0002 * * *$ & $0.43(0.20,0.65)$ & $0.0003 * * *$ & $0.47(0.23,0.7 \mathrm{I})$ & $0.0002 * * *$ \\
\hline $\begin{array}{l}\text { Timing of biliary drainage (hours) } \\
<24 \\
\geq 24\end{array}$ & $\begin{array}{l}\text { Ref } \\
2.99(-0.06,6.03)\end{array}$ & $0.057 \mid$ & $\begin{array}{l}\text { Ref } \\
2.81(-0.36,5.98)\end{array}$ & 0.0857 & $\begin{array}{l}\text { Ref } \\
3.10(-0.55,6.75)\end{array}$ & 0.0997 \\
\hline $\begin{array}{l}\text { Timing of biliary drainage (hours) } \\
<48 \\
\geq 48\end{array}$ & $\begin{array}{l}\text { Ref } \\
4.43(0.90,7.95)\end{array}$ & $0.0156 *$ & $\begin{array}{l}\text { Ref } \\
4.47(0.78,8.16)\end{array}$ & $0.0195 *$ & $\begin{array}{l}\text { Ref } \\
5.56(1.43,9.68)\end{array}$ & $0.0096 * *$ \\
\hline
\end{tabular}

Notes: data presented are $\beta$ s and $95 \%$ Cls. Adjust I model adjusts for age and sex; Adjust II model adjusts for adjust I + ECl, percutaneous drainage, cardiovascular dysfunction and bile duct stone as etiology. $* \mathrm{P}<0.05$, ** $\mathrm{P}<0.01$ and $* * * \mathrm{P}<0.001$

Abbreviation: $\mathrm{ECl}$ (vanWalRaven), Elixhauser comorbidity index. 


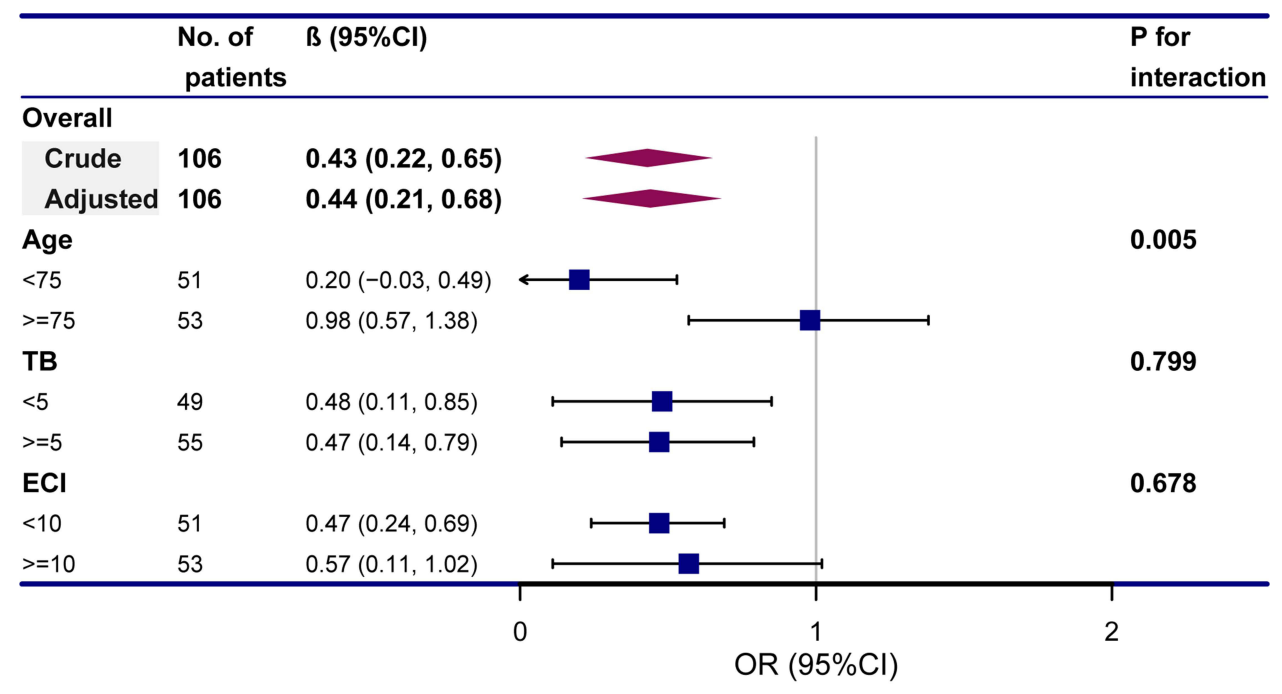

Figure 4 Subgroup analyses of the association between timing of biliary drainage (days) and length of stay of ICU.

Notes: Each stratification adjusted for all the factors (age, sex, bilirubin, ALP and ECI) except the stratification factor itself.



Figure 5 In-hospital mortality and 30-day mortality among different biliary drainage timing groups ( $<24$ hours, $24-48$ hours, and $>48$ hours).

of 49,722 cholangitis patients. ${ }^{9}$ Another population-based evidence with 107,253 patients included, stated that there was no difference in mortality between urgent ERCP (within 24 hours) and early ERCP (24 48 hours). ${ }^{19}$ Also three large studies demonstrated no differences in mortality and LOS, comparing weekday and weekend admissions. $^{9-11}$ These findings are congruent with our own, further supporting our hypothesis that urgent biliary drainage may not reduce the mortality and LOS in ICU, meaning a limited benefit on the severe acute cholangitis population. However, we may not confirm the conclusion with patients of BD timing after 24 hours, because relatively few patients fell into the category and reached the outcome of mortality. Interestingly, in the interaction

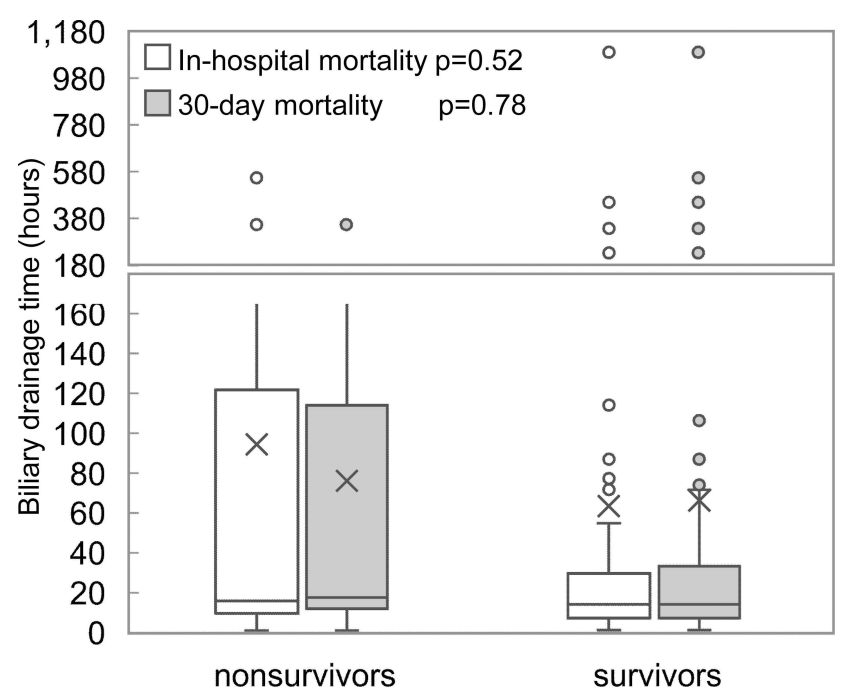

Figure 6 Distribution of biliary drainage timing in survivors and nonsurvivors by inhospital mortality and 30-day mortality.

analysis, the effects of delayed BD timing on 30-day mortality varied between different bacteremia conditions ( $\mathrm{P}$ for interaction $=0.01)$. For patients without bacteremia, delayed BD timing seemed more related to 30-day mortality as a risk factor $(\mathrm{OR}=1.26 ; 95 \%$ CI $0.24-1.53)$. Further investigation should be performed on this.

There were some studies that revealed early biliary drainage improved outcomes. A recent systematic review, including 9 observational studies and 2 database studies indicated decreased odds of mortality when ERCP was performed within 48 hours of admission, but comparison of within 24 hours and 24-48 hours was not conducted, because of inconsistent mortality data for those among 24 
Table 4 Multivariable Logistic Regression Models Evaluating the Association Between Timing of Biliary Drainage and Mortality

\begin{tabular}{|c|c|c|c|c|c|c|}
\hline \multirow[t]{2}{*}{ Variables } & \multicolumn{2}{|c|}{ Crude $(\mathrm{N}=106)$} & \multicolumn{2}{|c|}{ Model I $(N=106)$} & \multicolumn{2}{|c|}{ Model $2(\mathrm{~N}=106)$} \\
\hline & OR $(95 \% \mathrm{Cl})$ & $P$ value & OR $(95 \% \mathrm{Cl})$ & $P$ value & OR $(95 \% \mathrm{Cl})$ & $P$ value \\
\hline Timing of biliary drainage (days) & $1.03(0.95,1.10)$ & 0.4849 & $1.05(0.97,1.14)$ & 0.1889 & $1.03(0.93,1.13)$ & 0.9327 \\
\hline
\end{tabular}

(b) 30-day mortality

\begin{tabular}{|l|c|c|c|c|c|c|}
\hline \multirow{2}{*}{ Variables } & \multicolumn{2}{|c|}{ Crude $(\mathrm{N}=106)$} & \multicolumn{2}{c|}{ Model I $(\mathrm{N}=106)$} & \multicolumn{2}{c|}{ Model $2(\mathrm{~N}=106)$} \\
\cline { 2 - 7 } & OR $(95 \% \mathrm{Cl})$ & $\mathrm{P}$ value & OR $(95 \% \mathrm{Cl})$ & $\mathrm{P}$ value & OR $(95 \% \mathrm{Cl})$ & $\mathrm{P}$ value \\
\hline Timing of biliary drainage (days) & $\mathrm{I} .01(0.93,1.09)$ & $0.811 \mathrm{I}$ & $\mathrm{I} .05(0.96,1.14)$ & 0.2729 & $1.01(0.87,1.14)$ & 0.9461 \\
\hline
\end{tabular}

Notes: data presented are ORs and $95 \% \mathrm{Cls}$. Adjust I model adjusts for age and sex; Adjust II model adjusts for adjust I +ECl, percutaneous drainage, neurological dysfunction and bile duct stone as etiology.

Abbreviation: $\mathrm{ECl}$ (vanWalRaven), Elixhauser comorbidity index.

48 hours. $^{7}$ Another 166 acute cholangitis study suggested that early ERCP (within 24 hours) lowers 30-day mortality $(\mathrm{OR}=0.23 ; 95 \%$ CI $0.05-0.95 ; \mathrm{p}=0.04)$, but in the $43 \%$ of the population were malignant etiology, which was different from ours and most studies and might potentially impact the 30-day mortality. ${ }^{3}$ Further study about interaction between etiology and BD timing on outcomes should be conducted. Karvellas et al analyzed 260 patients with cholangitis-associated septic shock and proved that delayed biliary decompression $>12 \mathrm{~h}$ was associated with increased mortality $(\mathrm{OR}=3.40 ; 95 \%$ CI $1.12-10.31)$, however their timing of biliary decompression was defined as from the time of development of shock (mean arterial pressure $<65 \mathrm{mmHg}$ ) to the time of receipt of therapy and further comparison among patients with different intervals would need to be made to decide the optimal time and subgroup. ${ }^{2}$

To our knowledge, ours is a relatively large study on the association of biliary drainage timing and outcomes in the severe acute cholangitis population. Our results indicated that BD timing delay within 24 hours did not prolong the ICU LOS, nor increase the mortality significantly in the severe acute cholangitis population. A hasty intervention might increase the anesthetic risk and induce transient bacteremia that may lead to deterioration. Thus, in clinical, biliary decompression "as early as possible" strategy maybe not of the first importance for severe acute cholangitis patients, and could safely follow after initiation of antibiotics, adequate resuscitation and stabilization of organ function within 24 hours.

There were several important limitations of our work. The data from MIMIC-III, which was a single centered retrospective cohort database, might lead to selection biases of treatment and patients. Nonetheless, we applied rigorous inclusion and exclusion criteria and adjusted for important confounders to obtain reliable results. The sample size was small, but for the timing of $\mathrm{BD}$ in severe acute cholangitis population study, it was relatively large. Besides, most patients in this cohort having procedures within 24 hours, limits our ability to describe and analyze the outcomes of patients receiving intervention after 24 hours.

\section{Conclusion}

In the severe acute cholangitis population, 1-day delay of biliary drainage timing increased hospital LOS by 1.49 days. Delayed BD ( $>48$ hours) was associated with longer ICU LOS. However, the urgent BD (within 24 hours) was not associated with a decrease in mortality, nor significantly shorter ICU stay. Based on these, urgent biliary decompression may have limited benefit for severe acute cholangitis patients, and might be of secondary importance to adequate medical support care in the first day without increasing mortality. Thus, delaying BD by 24 hours, allowing adequate resuscitation, could possibly be one choice in managing severe acute cholangitis.

\section{Abbreviations}

BD, biliary drainage; MIMIC-III, Multiparameter Intelligent Monitoring in Intensive Care III; LOS, length of stay; ICU, intensive care unit; AC, acute cholangitis; TG18, Tokyo Guidelines 2018; BUN, blood urea nitrogen; WBC, white blood cell; INR, international normalized ratio; AST, aspartate aminotransferase; ALT, alanine aminotransferase; ALP, alkaline phosphatase; SOFA, Sequential Organ Failure 
Assessment; ECI, (vanWalRaven) Elixhauser comorbidity index; ERCP, endoscopic retrograde cholangiopancreatography; PBD, percutaneous biliary drainage.

\section{Data Sharing Statement}

The datasets used or analyzed during the current study are available from the corresponding author on reasonable request.

\section{Ethics Statement}

The studies involving human participants were reviewed and approved by The Massachusetts Institute of Technology and Beth Israel Deaconess Medical Center. Written informed consent to participate in this study was provided by the participants' legal guardian/next of kin.

\section{Acknowledgments}

I would extend my sincere gratitude to professor Jiyong Jing for his constant guidance, valuable suggestions and inspiring advice of the thesis. I am also deeply indebted to all group members of our research team for their patience and serious practical discussion for every reading through of the draft. Last but not least, special thanks should go to my beloved husband for his continuous support and encouragement.

\section{Funding}

This study was supported by the Medical Health Science and Technology Project of Zhejiang Provincial Health Commission. (No. 2021440354).

\section{Disclosure}

The authors declare that they have no conflicts of interest.

\section{References}

1. Lee F, Ohanian E, Rheem J, Laine L, Che K, Kim JJ. Delayed endoscopic retrograde cholangiopancreatography is associated with persistent organ failure in hospitalised patients with acute cholangitis. Aliment Pharmacol Ther. 2015;42(2):212-220. doi:10.1111/apt.13253

2. Karvellas CJ, Abraldes JG, Zepeda-Gomez S, et al. The impact of delayed biliary decompression and anti-microbial therapy in 260 patients with cholangitis-associated septic shock. Aliment Pharmacol Ther. 2016;44(7):755-766. doi:10.1111/apt.13764

3. Tan M, Schaffalitzky de Muckadell OB, Laursen SB. Association between early ERCP and mortality in patients with acute cholangitis. Gastrointest Endosc. 2018;87(1):185-192. doi:10.1016/j. gie.2017.04.009

4. Kiriyama S, Kozaka K, Takada T, et al. Tokyo Guidelines 2018: diagnostic criteria and severity grading of acute cholangitis (with videos). $J$ Hepatobiliary Pancreat Sci. 2018;25(1):17-30. doi:10.1002/jhbp.512
5. Khashab MA, Tariq A, Tariq U, et al. Delayed and unsuccessful endoscopic retrograde cholangiopancreatography are associated with worse outcomes in patients with acute cholangitis. Clin Gastroenterol Hepatol. 2012;10(10):1157-1161. doi:10.1016/j.cgh.2012.03.029

6. Navaneethan U, Gutierrez NG, Jegadeesan R, et al. Factors predicting adverse short-term outcomes in patients with acute cholangitis undergoing ERCP: a single center experience. World J Gastrointest Endosc. 2014;6(3):74-81. doi:10.4253/wjge.v6.i3.74

7. Iqbal U, Khara HS, Hu Y, et al. Emergent versus urgent ERCP in acute cholangitis: a systematic review and meta-analysis. Gastrointest Endosc. 2020;91(4):753-760. doi:10.1016/j. gie.2019.09.040

8. Khamaysi I, Taha R. ERCP for severe acute cholangitis: the earlier, the better. The Turkish Journal of Gastroenterology: The Official Journal of Turkish Society of Gastroenterology. 2020;31(1):78-79. doi:10.5152/tjg.2020.19103

9. Seo YJ, Hadaya J, Sareh S, Aguayo E, de Virgilio CM, Benharash P. National trends and outcomes in timing of ERCP in patients with cholangitis. Surgery. 2020;168(3):426-433. doi:10.1016/j. surg.2020.04.047

10. Inamdar S, Sejpal D, Ullah M, Trindade A. Weekend vs. Weekday Admissions for Cholangitis Requiring an ERCP: comparison of Outcomes in a National Cohort. Am J Gastroenterol. 2016;111 (3):405-410. doi:10.1038/ajg.2015.425

11. Tabibian J, Yang J, Baron T, Kane S, Enders F, Gostout C. Weekend Admission for Acute Cholangitis Does Not Adversely Impact Clinical or Endoscopic Outcomes. Dig Dis Sci. 2016;61(1):53-61. doi:10.1007/s10620-015-3853-z

12. Hakuta R, Hamada T, Nakai Y, et al. No Association of Timing of Endoscopic Biliary Drainage with Clinical Outcomes in Patients with Non-severe Acute Cholangitis. Dig Dis Sci. 2018;63(7):1937-1945. doi:10.1007/s10620-018-5058-8

13. Johnson A, Pollard T, Shen L, et al. MIMIC-III, a freely accessible critical care database. Scientific Data. 2016;3(1):160035. doi: $10.1038 /$ sdata.2016.35

14. van Walraven C, Austin P, Jennings A, Quan H, Forster A. A modification of the Elixhauser comorbidity measures into a point system for hospital death using administrative data. $J$ Medical Care. 2009;47(6):626-633. doi:10.1097/MLR.0b013e31819432e5

15. Kimura Y, Takada T, Kawarada Y, et al. Definitions, pathophysiology, and epidemiology of acute cholangitis and cholecystitis: tokyo Guidelines. J Hepatobiliary Pancreat Surg. 2007;14(1):15-26. doi:10.1007/s00534-006-1152-y

16. Andrew D, Johnson S. Acute suppurative cholangitis, a medical and surgical emergency. A review of ten years experience emphasizing early recognition. Am J Gastroenterol. 1970;54(2):141-154.

17. Aboelsoud M, Siddique O, Morales A, Seol Y, Al-Qadi M. Early biliary drainage is associated with favourable outcomes in critically-ill patients with acute cholangitis. Przeglad Gastroenterologiczny. 2018;13(1):16-21. doi:10.5114/pg.2018.74557

18. Schwed A, Boggs M, Pham X, et al. Association of Admission Laboratory Values and the Timing of Endoscopic Retrograde Cholangiopancreatography With Clinical Outcomes in Acute Cholangitis. JAMA Surg. 2016;151(11):1039-1045. doi:10.1001/ jamasurg.2016.2329

19. Parikh MP, Wadhwa V, Thota PN, Lopez R, Sanaka MR. Outcomes Associated With Timing of ERCP in Acute Cholangitis Secondary to Choledocholithiasis. Clin Gastroenterol. 2018;52(10):e97-e102. doi:10.1097/MCG.0000000000000982 


\section{Publish your work in this journal}

The International Journal of General Medicine is an international, peer-reviewed open-access journal that focuses on general and internal medicine, pathogenesis, epidemiology, diagnosis, monitoring and treatment protocols. The journal is characterized by the rapid reporting of reviews, original research and clinical studie across all disease areas. The manuscript management system is completely online and includes a very quick and fair peer-review system, which is all easy to use. Visit http://www.dovepress.com/ testimonials.php to read real quotes from published authors.

Submit your manuscript here: https://www.dovepress.com/international-journal-of-general-medicine-journal 